\title{
Valor diagnóstico da punção-biópsia pleural: experiência em um serviço de clínica médica*
}

\author{
Anete Trajman ${ }^{1}$, Marcia Teresa Belo ${ }^{2}$, Eleny Guimarães Teixeira ${ }^{3}$, Epaminondas Belo NetO ${ }^{2}$, \\ Debora FERNANDES RodRIGUES ${ }^{4}$, MARIO MonjARdim CASTELLO BRANCO ${ }^{5}$
}

Objetivo: Avaliar o valor da punção-biópsia pleural no diagnóstico das doenças inflamatórias da pleura. Métodos: Foi feito um estudo retrospectivo de 82 toracocenteses realizadas durante um período de 42 meses em uma enfermaria de clínica médica no Rio de Janeiro. Os aspectos bioquímicos, citológicos e bacteriológicos do líquido pleural e o exame histopatológico do fragmento pleural foram correlacionados com o diagnóstico final. A sensibilidade, especificidade e os valores preditivos da concentração protéica e da percentagem de linfócitos no líquido pleural foram calculados utilizando diferentes valores de corte. Resultados: Dos 82 pacientes, 73 (89\%) tinham tuberculose.

Todos os pacientes com menos de 35 anos tinham tuberculose. O valor preditivo negativo para o diagnóstico de tuberculose aumentou de $17,1 \%$ para $66,7 \%$ utilizando $4,5 \mathrm{~g} / \mathrm{dL}$ e $2,5 \mathrm{~g} / \mathrm{dL}$, respectivamente, como valores de corte para a concentração de proteínas no líquido pleural. $\mathrm{O}$ valor preditivo negativo do achado de $70 \%$ de linfócitos no líquido pleural foi de $100 \%$ e o seu valor preditivo positivo, de $94,2 \%$. A pesquisa de BAAR no líquido pleural foi negativa nas 82 amostras. A sensibilidade do exame histopatológico da pleura foi de 69,2\% para o diagnóstico de tuberculose. Conclusões: A tuberculose foi a causa mais comum de derrame pleural em todas as faixas etárias. O exame que mais contribuiu para confirmar este diagnóstico foi a análise histopatológica. Os autores sugerem que a punção pleural e a biópsia sejam realizadas simultaneamente nas populações em que a tuberculose tenha alta prevalência. (J Pneumol 2000;27(1):11-16)

\section{Efficacy of thoracentesis and pleural biopsy in the diagnosis of pleural inflammatory diseases: experience in an internal medicine ward}

Objective: To evaluate the efficacy of thoracentesis and pleural biopsy in the diagnosis of pleural inflammatory diseases. Methods: A retrospective study of 82 thoracenteses performed over a 42month period in an internal medicine ward in Rio de Janeiro was conducted. Biochemical, cytological, and microbiological features of the pleural effusion, as well as the histopathological examination of the pleural tissue, were analyzed according to the final diagnosis. The sensitivity, sensibility, and predictive efficacy in the diagnosis of tuberculosis were calculated using different cut-off values of protein concentration and lymphocyte percentage. Results: Of the 82 patients, 73 (89\%) had tuberculosis. This was the only diagnosis among patients aged 35 years or less. The negative predictive value $(P V)$ raised from $17.1 \%$ to $66.7 \%$ when 4.5 and $2.5 \mathrm{~g} / \mathrm{dl}$, respectively, were used as cut-off values for protein concentration in the pleural fluid. Using $70 \%$ as the cut-off value for lymphocyte percentage in pleural fluid, negative PV was $100 \%$ and positive PV was 94.2\%. Acid fast bacilli staining of the pleural fluid was negative in all samples. The sensitivity of

* Trabalho realizado na $7^{\text {a }}$ Enfermaria do Hospital Geral da Santa Casa de Misericórdia do Rio de Janeiro, Universidade Gama Filho e Fundação Técnico-Educacional Souza Marques. Parcialmente financiado pela Fundação de Amparo à Pesquisa do Estado do Rio de Janeiro-Faperj (E-26/150.938/96, E-26/150.304/99).

1. Professora Adjunta de Clínica Médica.

2. Professor Assistente de Clínica Médica.

3. Professora Auxiliar de Ensino de Clínica Médica.
4. Acadêmica de Medicina.

5. Professor Titular de Clínica Médica.

Endereço para correspondência - Anete Trajman, Rua Macedo Sobrinho, 74/203 - 22271-080 - Rio de Janeiro, RJ. Fax (21) 532-1661; E-mail: atrajman@centroin.com.br

Recebido para publicação em 30/3/00. Reapresentado em 27/ 7/00. Aprovado, após revisão, em 13/11/00. 
the histopathological examination of the pleural tissue was $69.2 \%$ for the diagnosis of tuberculosis. Conclusions: Tuberculosis was the most common cause of pleural effusion in all age groups. Histopathological examination had the highest sensitivity to confirm tuberculosis. The authors suggest that, in populations with a high prevalence of tuberculosis, pleural tissue biopsy should be performed simultaneously with thoracentesis.

Descritores - Pleurisia. Biópsia por agulha. Tuberculose. Serviços de saúde.

Key words - Pleurisy. Needle biopsy. Tuberculosis. Health services.

\section{INTRODUÇÃO}

O derrame pleural pode ser uma manifestação de doenças sistêmicas, como a insuficiência cardíaca e a síndrome nefrótica, ou de doenças inflamatórias da pleura, como as infecções e as neoplasias. No primeiro caso, o derrame apresenta características de transudato, com baixas concentrações de proteínas, de desidrogenase lática (LDH) $e$ de adenosina deaminase (ADA) e pequeno número de células. Nestes casos, entretanto, não há necessidade de examinar o líquido; o diagnóstico é feito preferencialmente através do quadro clínico e de outros exames complementares. Inversamente, as doenças inflamatórias da pleura resultam na produção de exsudato, rico em proteínas, enzimas e células.

Quando há suspeita de doença inflamatória pleural, o procedimento diagnóstico de escolha é a toracocentese. O procedimento, quando possivel, deve ser feito por um especialista e o líquido deve ser sempre analisado. $\mathrm{O}$ simples esvaziamento do derrame é inaceitável, exceto nos casos em que há dispnéia intensa, quando então é feita uma toracocentese de alívio. Ainda assim, parte do líquido deve ser reservada para posterior análise.

O diagnóstico pode ser estabelecido com base nas características bioquímicas, citológicas e bacteriológicas do líquido pleural. Nos países desenvolvidos, onde a prevalência de tuberculose é baixa, a biópsia pleural é feita somente quando a análise do líquido não esclarece o diagnóstico. No Brasil, a biópsia de pleura é feita no mesmo tempo cirúrgico da toracocentese quando há suspeita clínica de tuberculose ou câncer ${ }^{(1)}$. As complicações do procedimento são raras e incluem pneumotórax, hemotórax, reflexo vagovagal e dor torácica.

No Brasil, uma das causas mais freqüentes de derrame pleural é a tuberculose $e^{(2)}$. Este é um diagnóstico difícil, pois a sensibilidade dos exames bacteriológicos é baixa nas amostras de líquido pleural. O diagnóstico usualmente se baseia em critérios histopatológicos ou na presença de líquido pleural exsudativo com franco predomínio de linfócitos em pacientes jovens reatores ao teste tuberculínico ${ }^{(3)}$.
Siglas e abreviaturas utilizadas neste trabalho

LDH - Desidrogenase lática

ADA - Adenosina deaminase

BAAR - Bacilo ácido-alcoolrresistente

IFN- $\gamma$ - Interferon gama

PCR - Reação em cadeia pela polimerase

O objetivo do presente estudo foi avaliar a contribuição da toracocentese e da biópsia pleural para o diagnóstico das doenças inflamatórias da pleura em um serviço de clínica médica que presta atendimento à população carente do Rio de Janeiro, município com as maiores taxas de incidência e de mortalidade por tuberculose no país ${ }^{(4)}$.

\section{MÉTODOS}

Foi realizado um estudo retrospectivo no Serviço de Clínica Médica da $7^{a}$ Enfermaria do Hospital Geral da Santa Casa de Misericórdia do Rio de Janeiro. Trata-se de uma enfermaria masculina que possui um convênio com a Secretaria de Saúde do Estado para internação de pacientes com Aids. O serviço possui um setor de Pneumologia, onde são realizados exames complementares para todas as enfermarias do hospital. As toracocenteses são realizadas em pacientes com suspeita clínica de doença inflamatória da pleura e a biópsia pleural é feita no mesmo procedimento. Um registro de todos os procedimentos é mantido nesse setor. A partir desse registro, os prontuários referentes às toracocenteses realizadas no período de abril de 1996 a setembro de 1999 foram revistos.

Foram analisados a idade, o sexo, a presença de infecção pelo HIV(5) e o diagnóstico final na alta. Os critérios diagnósticos de tuberculose utilizados no serviço são aqueles recomendados pelo Ministério da Saúde ${ }^{(6)}$ e pelo I Consenso Brasileiro de Tuberculose ${ }^{(3)}$. Em resumo, o diagnóstico de certeza é estabelecido quando qualquer amostra de secreção ou tecido apresenta pesquisa de bacilo ácido-alcoolrresistente (BAAR) ou cultura para Mycobacterium tuberculosis positivas ou ainda quando há granuloma com necrose caseosa em qualquer tecido. O diagnóstico de probabilidade baseia-se na presença de líquido pleural rico em proteínas, com predomínio franco de linfócitos em paciente com menos de 35 anos apresentando quadro clínico sugestivo e teste tuberculínico reator.

Os pacientes foram divididos em três grupos de acordo com o diagnóstico: tuberculose confirmada, tuberculose 
provável e outras doenças. As características bioquímicas e citológicas do líquido pleural foram comparadas de acordo com os diferentes grupos e com a presença ou não da infecção pelo HIV. A sensibilidade, a especificidade e os valores preditivos para o diagnóstico de tuberculose foram calculados utilizando diferentes valores de corte da concentração de proteínas e da percentagem de linfócitos no líquido pleural.

As variáveis categóricas foram comparadas nos diferentes grupos utilizando o teste do qui-quadrado $e$, as variáveis numéricas, pelo teste de Kruskal-Wallis.

\section{REsUlTADOS}

No período do estudo foram realizadas toracocenteses em 82 pacientes. Setenta (85\%) eram homens e a idade mediana foi de 35 (13-85) anos. O teste sorológico antiHIV foi feito em 61 pacientes e foi positivo em 15 (25\%).

Dos 82 pacientes, apenas um não apresentava doença inflamatória da pleura. Tratava-se de um paciente de 67 anos internado com insuficiência cardíaca congestiva, cujo derrame pleural unilateral à direita não regrediu apesar da melhora do quadro. A toracocentese foi realizada para afastar outro eventual diagnóstico. Na Tabela 1 estão apresentados os diagnósticos finais dos 82 pacientes.

Setenta e três (89\%) pacientes tinham tuberculose. Este diagnóstico foi confirmado por cultura do líquido pleural em três (4\%) pacientes e pela presença de granuloma com necrose caseosa em 43 (59\%). Dois casos com cultura

TABELA 1

Diagnóstico final dos 82 pacientes submetidos à toracocentese

\begin{tabular}{|c|c|}
\hline Diagnóstico & $\mathbf{N}(\%)$ \\
\hline Tuberculose confirmada & $46(56 \%)$ \\
\hline Tuberculose provável & $27(33 \%)$ \\
\hline Adenocarcinoma de pulmão & $4 \quad(5 \%)$ \\
\hline Empiema & $2(2 \%)$ \\
\hline Derrame parapneumônico & $2(2 \%)$ \\
\hline Insuficiência cardíaca & $1 \quad(1 \%)$ \\
\hline
\end{tabular}

positiva também apresentaram granuloma, totalizando 45 (62\%) pacientes com critério histopatológico de tuberculose. Nos outros 27 (37\%) pacientes, foi estabelecido o diagnóstico de probabilidade de tuberculose.

A idade mediana dos pacientes com tuberculose foi inferior à dos com outros diagnósticos: 33 (13-85) anos versus 68,5 (51-77) anos, $p=0,0001$. A tuberculose foi o único diagnóstico entre os pacientes com menos de 35 anos.

Uma amostra de líquido pleural foi obtida nos 82 procedimentos realizados e fragmentos de pleura, em 72 (88\%). Dentre os fragmentos de pleura obtidos nesses 72,65 provieram de pacientes com diagnóstico de tuberculose. Em 45 destes espécimens (69\%) havia granuloma. Nos outros 27, havia um infiltrado inflamatório inespecífico. Não houve infiltração maligna em nenhum dos fragmentos obtidos; o exame citológico do líquido, no entanto, demonstrou células malignas nos quatro casos de adenocarcinoma.

A concentração de proteínas e a percentagem de linfócitos foram superiores nos pacientes com diagnóstico de tuberculose, tanto de certeza quanto de probabilidade. As características bioquímicas e citológicas do líquido pleural nos diferentes grupos estão resumidas na Tabela 2.

Dentre os 73 pacientes com tuberculose, 44 tinham concentração de proteína no líquido pleural superior a $4,5 \mathrm{~g} / \mathrm{dL}$ e 29 , inferior a $4,5 \mathrm{~g} / \mathrm{dL}$. Dentre estes últimos, 12 tinham concentração de proteína entre 3,5 e 4,5g/ $\mathrm{dL}$; dez, entre 3 e 3,5g/dL; seis, entre 2,5 e $3,0 \mathrm{~g} / \mathrm{dL}$ e um, inferior a $2,5 \mathrm{~g} / \mathrm{dL}$. Dentre os pacientes com diagnóstico de probabilidade de tuberculose, $56 \%$ tinham proteína inferior a $4,5 \mathrm{~g} / \mathrm{dL}$.

$\mathrm{Na}$ Tabela 3 encontram-se a sensibilidade, a especificidade, a acurácia e os valores preditivos para o diagnóstico de tuberculose de acordo com diferentes valores de corte para a concentração de proteínas e para a percentagem de linfócitos. Nesta tabela, observa-se que o valor preditivo negativo aumentou de $17,1 \%$ para $66,7 \%$ com os valores de corte de 4,5 e 2,5, respectivamente, com redução modesta do valor preditivo positivo de $100 \%$ para $94,2 \%$.

TABELA 2

Características bioquímicas e citológicas do líquido pleural de acordo com os diferentes grupos

\begin{tabular}{lcccc}
\hline & $\begin{array}{c}\text { Tuberculose } \\
\text { confirmada } \\
(\mathbf{n}=\mathbf{4 6})\end{array}$ & $\begin{array}{c}\text { Tuberculose } \\
\mathbf{p r o v a ́ v e l} \\
(\mathbf{n = 2 7 )}\end{array}$ & $\begin{array}{c}\text { Outros } \\
\mathbf{( n = 9 )}\end{array}$ & $\begin{array}{c}\text { Valor } \\
\text { de } \boldsymbol{p}\end{array}$ \\
\hline Proteínas g/dL & $4,6(2,4-8,9)$ & $4,4(2,5-5,4)$ & $3,2(1,9-4,2)$ & $\mathbf{0 , 0 0 2}$ \\
LDH UI/L & $360(57-1510)$ & $540(66-837)$ & $337(109-643)$ & 0,66 \\
Citometria (céls/mm $\left.{ }^{3}\right)$ & $390(10-32.000)$ & $370(30-32.000)$ & $640(80-10.000)$ & 0,68 \\
Mononucleares $(\%)$ & $98(70-100)$ & $99(70-100)$ & $30(0-85)$ & $\mathbf{0 , 0 0 0 6}$ \\
\hline
\end{tabular}


Todos os pacientes com tuberculose tinham pelo menos $70 \%$ de células mononucleares no líquido pleural. O valor preditivo negativo utilizando este valor de corte foi de $100 \%$ e o seu valor preditivo positivo, de $94,2 \%$. A pesquisa de BAAR no líquido pleural foi negativa nas 82 amostras.

Todos os 15 pacientes infectados pelo HIV tiveram o diagnóstico final de tuberculose pleural: 11 de certeza e quatro de probabilidade. A prevalência de infecção pelo HIV nos pacientes com tuberculose foi de $26 \%$ (15/57 pacientes testados). A concentração de células no líquido dos pacientes co-infectados pelo HIV foi inferior quando comparada com a dos sem a co-infecção. Embora houvesse tendência a menor concentração de proteínas nos pacientes infectados pelo HIV, a diferença não foi estatisticamente significativa. A comparação das características laboratoriais do líquido e a presença de granulomas no tecido dos pacientes com tuberculose, com e sem co-infecção pelo HIV, está demonstrada na Tabela 4.

Houve uma única complicação do procedimento: um paciente desenvolveu um pequeno hemotórax, sem re- percussões hemodinâmicas, e o quadro regrediu espontaneamente.

\section{DISCUSSÃO}

Diante de um paciente com derrame pleural, o primeiro passo é o de procurar estabelecer, através da anamnese e do exame físico, se o derrame resulta de doença primária da pleura ou de doença em outro órgão. Se há suspeita de doença inflamatória da pleura, a toracocentese para análise do líquido pleural está indicada. Em nossa amostra, apenas uma punção foi feita em um paciente com insuficiência cardíaca, o que evidencia que o julgamento clínico pode ser bastante específico na identificação de doenças inflamatórias da pleura.

Quando a toracocentese confirma a natureza exsudativa do derrame pleural, está indicada a biópsia do tecido pleural. O rendimento diagnóstico da punção-biópsia de pleura depende de vários fatores, entre eles a experiência do profissional que a realiza, o treinamento do patologista e a prevalência das diferentes doenças. Em nossa

TABELA 3

Sensibilidade, especificidade, acurácia e valores preditivos positivo e negativo da concentração de proteínas e da percentagem de linfócitos no líquido pleural de acordo com os diferentes valores de corte utilizados

\begin{tabular}{cccccc}
\hline & Sensibilidade & Especificidade & Acurácia & VP+ & VP- \\
\hline Proteína & & & & \\
$2,5 \mathrm{~g} / \mathrm{dL}$ & $98,5 \%$ & $33,3 \%$ & $93,2 \%$ & $94,3 \%$ & $66,7 \%$ \\
$3,0 \mathrm{~g} / \mathrm{dL}$ & $91,0 \%$ & $50,0 \%$ & $87,7 \%$ & $95,3 \%$ & $33,3 \%$ \\
$3,5 \mathrm{~g} / \mathrm{dL}$ & $85,1 \%$ & $50,0 \%$ & $82,2 \%$ & $95,0 \%$ & $23,1 \%$ \\
$4,0 \mathrm{~g} / \mathrm{dL}$ & $76,1 \%$ & $83,3 \%$ & $75,3 \%$ & $98,1 \%$ & $23,8 \%$ \\
$4,5 \mathrm{~g} / \mathrm{dL}$ & $56,7 \%$ & $100 \%$ & $60,3 \%$ & $100 \%$ & $17,1 \%$ \\
\hline Linfócitos & & & & & \\
$70 \%$ & $100 \%$ & $55,5 \%$ & $94,6 \%$ & $94,2 \%$ & $100 \%$ \\
$80 \%$ & $92,3 \%$ & $66,7 \%$ & $89,2 \%$ & $95,2 \%$ & $54,5 \%$ \\
$90 \%$ & $89,2 \%$ & $77,7 \%$ & $87,8 \%$ & $96,7 \%$ & $50,0 \%$ \\
\hline VP: valor preditivo & & & & &
\end{tabular}

TABELA 4

Características laboratoriais do líquido e tecido pleural segundo a presença da infecção pelo HIV

\begin{tabular}{lccc}
\hline & $\begin{array}{c}\text { HIV positivo } \\
(\mathbf{n = 1 5 )}\end{array}$ & $\begin{array}{c}\text { HIV negativo } \\
(\mathbf{n}=\mathbf{5 8})\end{array}$ & $\begin{array}{c}\text { Valor } \\
\text { de } \boldsymbol{p}\end{array}$ \\
\hline Proteínas g/dL & $3,9(2,5-8,9)$ & $4,5(2,7-6,0)$ & 0,06 \\
$\mathrm{LDH} \mathrm{UI/L}$ & $244(161-540)$ & $411(57-837)$ & 0,17 \\
Citometria $\left(c e ́ l s / \mathrm{mm}^{3}\right)$ & $190(10-32.000)$ & $405(10-32.000)$ & $\mathbf{0 , 0 2}$ \\
Mononucleares $(\%)$ & $98(75-100)$ & $98(70-100)$ & 0,42 \\
Granuloma & $10 / 15(67 \%)$ & $28 / 36(78 \%)$ & 0,49 \\
\hline
\end{tabular}


série, foi possivel obter líquido em $100 \%$ dos procedimentos e fragmentos de tecido pleural em $88 \%$.

No Brasil, onde é epidêmica, a tuberculose é a causa mais freqüente de doença inflamatória pleural ${ }^{(2)}$. Com efeito, em nossa amostra, $89 \%$ dos derrames pleurais foram de origem tuberculosa. Nos pacientes co-infectados pelo HIV, essa percentagem se elevou para $100 \%$.

Esses dados contrastam com os da literatura dos países desenvolvidos. Nos Estados Unidos da América, a causa mais comum de derrame pleural exsudativo é a pneumonia bacteriana, tanto em pacientes imunocompetentes quanto naqueles infectados pelo $\mathrm{HIV}^{(7,8)}$. As micobacterioses figuram, junto com a pneumocistose $e$ as infecções fúngicas, como causas infreqüentes de derrame pleural nos pacientes com Aids ${ }^{(8)}$. No período de 42 meses de nosso estudo, nenhuma dessas condições cursou com derrame pleural, apesar do grande número de pacientes portadores de Aids internados.

A tuberculose pleural é de difícil diagnóstico, pois a sensibilidade da pesquisa de BAAR e da cultura para $M$. tuberculosis no líquido e no tecido pleural é baixa. Com freqüência, o tratamento é iniciado com base nos critérios de probabilidade, que incluem idade inferior a 35 anos, teste tuberculínico positivo, concentração de proteína alta e predomínio de linfócitos no líquido pleural. Em nossa amostra, todos os pacientes com menos de 35 anos tinham tuberculose. A idade mínima dos pacientes com outros diagnósticos foi de 51 anos. Entretanto, a tuberculose foi freqüente (61\%) entre os pacientes com mais de 50 anos e deve ser sempre suspeitada diante de um derrame pleural em qualquer faixa etária.

Os critérios diagnósticos de probabilidade para a tuberculose pleural não estão claramente estabelecidos. Os valores de corte propostos para a concentração de proteínas e percentual de linfócitos são controversos. Fiúza de Melo $^{(9)}$ propôs o valor de $4,5 \mathrm{~g} / \mathrm{dL}$ de proteína e $90 \%$ de linfócitos, com um valor preditivo positivo de $99,5 \%$. Já Conde e Kritski ${ }^{(10)}$ propuseram o valor de corte em $80 \%$ de linfócitos, na presença de pelo menos 1.000 células $/ \mathrm{mm}^{3}$. Em nossa amostra, $29(40 \%)$ pacientes com diagnóstico final de tuberculose tinham no líquido a concentração protéica inferior a $4,5 \mathrm{~g} / \mathrm{dL}$. Esta percentagem foi ainda maior (56\%) entre os pacientes com diagnóstico de probabilidade de tuberculose. Isso significa que, com o valor de corte de $4,5 \mathrm{~g} / \mathrm{dL}$, grande parte dos pacientes com tuberculose pleural não preencheria os critérios de um exsudato.

Poucos pacientes em nossa série foram submetidos ao teste tuberculínico e esses dados não foram apresentados. A sua interpretação é difícil em populações com alta prevalência de tuberculose.

Já o diagnóstico de certeza da tuberculose se baseia com freqüência na análise histopatológica, através da demonstração de granulomas com necrose caseosa. No entanto, granulomas não são lesões patognomônicas da tuberculose. Criptococose, sarcoidose e micobacterioses atípicas são exemplos de doenças em que podem ser observadas tais lesões; devem ser consideradas no diagnóstico diferencial, embora o derrame pleural seja infreqüente nessas condições. Em nosso estudo, a presença de granulomas foi o único critério presente em $59 \%$ dos pacientes com tuberculose e contribuiu para o diagnóstico final em outros $3 \%$. A sensibilidade do exame histopatológico atingiu $69,2 \%$ quando computados somente os pacientes em quem se obteve tecido pleural. No entanto, esse exame não contribuiu para os outros diagnósticos, com destaque para quatro resultados negativos em pacientes com adenocarcinoma identificado no estudo citológico do líquido pleural.

A sensibilidade da pesquisa direta do BAAR em nossos pacientes foi de $0 \%$. Embora não tenha sido possível realizar a cultura em todos os pacientes, esse exame contribuiu para o diagnóstico em apenas $4 \%$ dos casos. A sensibilidade dos exames bacteriológicos é referida na literatura como inferior a $20 \%$ e é pouco provável que estes exames sejam mais sensiveis que o histopatológico no diagnóstico da tuberculose pleural em nosso meio. Ademais, a cultura é lenta e, mesmo com técnicas que a aceleram, o resultado pode demorar até duas semanas.

Exames promissores para uso na rotina incluem a dosagem da ADA, do interferon gama (IFN- $\gamma$ ) e a reação em cadeia pela polimerase (PCR) para a identificação do DNA do bacilo nos espécimens pleurais e pulmonares. No entanto, a acurácia desses exames ainda não foi estabelecida. Foi sugerido que a dosagem da ADA no líquido pleural tem alta sensibilidade e especificidade $e^{(11)}$. No entanto, outros trabalhos mostraram que a especificidade do exame é baixa e que doenças como a artrite reumatóide e o carcinoma broncogênico também podem cursar com valores altos de ADA no líquido pleural(12). Ademais, os kits de laboratório disponiveis para a sua dosagem têm rendimento muito baixo. Giusti(13) descreveu um método de dosagem da ADA que permite diferenciar a ADA-1 da ADA2. Esta última isoenzima parece estar aumentada apenas na tuberculose $e^{(14)}$. Por sua vez, o PCR não foi aprovado para uso em espécimes não respiratórios ${ }^{(15)}$. Foi ainda demonstrado que os derrames pleurais de origem tuberculosa possuem alta concentração de IFN- $\gamma^{(16)}$ e foi sugerido que sua dosagem poderia auxiliar no diagnóstico da doença. Em estudo recente, verificamos que a concentração desta citocina no líquido pleural de pacientes com a co-infecção tuberculose/Aids é semelhante àquela dos pacientes não infectados pelo HIV ${ }^{(17)}$. O valor desses novos exames no diagnóstico da tuberculose pleural ainda não foi estabelecido e estudos complementares são necessários. 
Em conclusão, a tuberculose foi a causa mais comum de derrame pleural em todas as faixas etárias na presente série. O exame que mais contribuiu para afirmar esse diagnóstico foi a análise histopatológica do fragmento de pleura. Embora este exame não tenha sido útil para o diagnóstico no pequeno grupo de pacientes com adenocarcinoma, sugerimos que, nas populações com alta prevalência de tuberculose, a toracocentese e a biópsia de pleura sejam realizadas simultaneamente.

Em relação ao valor de corte ideal da concentração protéica e da percentagem de mononucleares do líquido pleural para o diagnóstico da tuberculose, outros estudos, incluindo um número maior de pacientes com outros diagnósticos, são necessários.

\section{REFERÊNCIAS}

1. Kritski AL, Conde MB, Muzy de Souza GR. Investigação diagnóstica de tuberculose. In: Tuberculose. Do ambulatório à enfermaria. Rio de Janeiro: Atheneu, 1999;53-103.

2. Tarantino AB, Chibante MAS. Derrames pleurais. In: Tarantino AB, ed. Doenças pulmonares. Rio de Janeiro: Guanabara Koogan, 1997; 905-956.

3. I Consenso Brasileiro de Tuberculose. J Pneumol 1997;23:294-301.

4. Secretaria Municipal de Saúde. Tuberculose no município do Rio de Janeiro: revisão dos casos notificados de 1995 a 1998. Bol Epidemiol 1999;6.

5. Brasil. Ministério da Saúde. Manual de diretrizes dos Centros de Testagem e Aconselhamento-CTA: Coordenação Nacional de DST e Aids.
Brasilia, 1999: 32 p. Disponível em http://www.Aids.gov.br/diretrizes-mancta.htm.

6. Brasil. Ministério da Saúde. Coordenação Nacional de Pneumologia Sanitária. Manual de Tuberculose. J Pneumol 1997;23:281-293.

7. Strange C, Sahn AS. The definitions and epidemiology of pleural space infection. Semin Respir Infect 1999;14:3-8.

8. Joseph J, Strange C, Sahn AS. Pleural effusions in hospitalized patients with Aids. Ann Intern Med 1993;118:856-859.

9. Fiuza de Melo FA. Atividade da adenosina deaminase (ADA) isolada $e$ combinada a outras variáveis no diagnóstico da tuberculose pleural e sua aplicabilidade em infectados pelo vírus da imunodeficiência humana. Tese (doutorado), Faculdade de Medicina, Unifesp, São Paulo, 1997.

10. Conde MB, Kritski AL. Evaluation of presumptive diagnosis of pleuro pulmonary tuberculosis on Brazil. In: Anais do "World Congress on Tuberculosis", Bethesda - EUA; 1992; 19-C, Abstract 3-13.

11. Burgess LJ, Maritz FJ, Le Roux I, et al. Use of adenosine deaminase as a diagnostic tool for tuberculous pleurisy. Thorax 1995;50:672-674.

12. Light RW. Pleural diseases. 3rd ed. Baltimore: Williams \& Wilkins, 1995.

13. Giusti G. Adenosine deaminase. In: Bergmeyer HU, ed. Methods of enzymate analysis. New York: Academic Press, 1974; 1092-1099.

14. Gakis C. Adenosine deaminase (ADA) isoenzymes ADA1 and ADA2: diagnostic and biological role. Eur Respir J 1996;9:632-633.

15. American Thoracic Society. Rapid diagnostic tests for tuberculosis. What is the appropriate use? Am J Respir Crit Care Med 1997;155:18041814.

16. Barnes PF, Lu S, Abrams JS, Wang E, Yamamura M, Modlin RL. Cytokine production at the site of disease in human tuberculosis. Infect Immun 1993;61:3482-3489.

17. Trajman A, Belo MTCT, Teixeira EG, Oliveira MP, et al. Pleural fluid interleukin profile in HIV-associated tuberculosis. Am J Resp Crit Care Med 2000;161:A649. 